\title{
EVIDENCIAS RESPECTO A LA MEDIACIÓN PENAL EN LA NORMA EUROPEA*
}

\author{
EVIDENCE REGARDING VICTIM-OFFENDER \\ MEDIATION IN EUROPEAN LAW
}

\author{
Irene Soler-NoguerA** \\ EMILIA IGLESIAS-ORTUÑO*** \\ Fecha de recepción: 28 de mayo de 2016 \\ Fecha de aceptación: 11 de junio de 2016 \\ Disponibilidad en línea: 30 de junio de 2016
}

\begin{abstract}
PARA CITAR ESTE ARTÍ́CULO / TO CITE THIS ARTICLE Soler-Noguera, Irene \& Iglesias-Ortuño, Emilia, Evidencias respecto a la mediación penal en la norma europea, 28 International Law, Revista Colombiana de Derecho Internacional, 283-320 (2016). http://dx.doi.org/10.11144/ Javeriana.il 14-28.ermp

doi:10.11144/Javeriana.i114-28.ermp
\end{abstract}

* Este artículo se fundamenta en el trabajo Mediación penal y justicia restaurativa en Europa. Estudio exploratorio de la legislación vigente en mediación penal de los países pertenecientes a la Unión Europea, realizado durante el máster de mediación, Universidad de Murcia, España.

** Graduada en criminología, Universidad de Alicante, España. Máster en mediación y doctoranda del programa de criminología, Universidad de Murcia, España. Contacto: irenesolernoguera@ gmail.com

*** Diplomada en trabajo social. Máster en mediación y doctora en intervención social y mediación, Universidad de Murcia, España. Contacto: ea.iglesiasortuno@um.es 


\section{RESUMEN}

El presente artículo plantea como objetivo principal de investigación conocer la normativa vigente en mediación penal de los países pertenecientes a la Unión Europea, para estudiar y comparar los rasgos característicos de esta normativa entre los países europeos. Para este fin se ha utilizado una metodología de investigación cualitativa basada en el análisis documental por categorías con el software MaxQDA para comparar las diversas legislaciones seleccionadas. Los países estudiados han sido Alemania, Austria, Bélgica, Finlandia, Francia, Hungría, Italia, Luxemburgo, Polonia, Portugal y República Checa. Los hallazgos han sido que la normativa específica en esta materia (que aparece sobre todo en Códigos Penales y Procesales más que en leyes autónomas) tiene muy poco tiempo de desarrollo, está fundamentada para delitos menos graves y hay muy poca fundamentación teórica de la mediación penal en las leyes. La sistematización de la legislación por categorías con ayuda de un programa informático ha permitido construir una visión general de la mediación penal en Europa muy útil para su desarrollo y sobre todo para darle visibilidad a esta práctica restaurativa.

Palabras clave: Legislación; mediación; justicia restaurativa; análisis documental; infracciones penales y consecuencias 


\begin{abstract}
This article presents the main objective of research meet current regulations in victim-offender mediation of the countries belonging to the European Union, to study and compare the characteristics of those rules across European countries. For this purpose we used a qualitative research methodology based on document analysis by categories through a MaxQDA software selected to compare the various laws. The countries studied were German, Austria, Belgium, Finland, France, Hungary, Italy, Luxemburg, Poland, Portugal and Czech Republic. The results found were that specific legislation in this area (which are mainly in Criminal and Procedural laws more than autonomous law) has very little development time, which is founded for less serious crimes and that there is little theoretical basis of victim-offender mediation law. Through the systematization by categories through a computer program of legislation it has been able to build an overview of victim-offender mediation in Europe very useful for the development of it, and especially to give visibility to this restorative practice.
\end{abstract}

Keywords: Legislation; mediation; restorative justice; document analysis; criminal offenses and consequences

SUMARIO

Introducción.- I. Fundamentos teóricos.- II. Metodología.- III. ResulTADOS.- CONCLUSIONES Y DISCUSIÓN.- BiBLIOGRAFÍA. 
En la actualidad, la mediación como sistema de resolución de conflictos está experimentando un gran crecimiento en España y en los países de su entorno más cercano ${ }^{1}$. Asimismo también ha llegado la mediación a la justicia, sobre todo en asuntos civiles y familiares, pero sin olvidar el ámbito penal ${ }^{2}$.

El sistema de justicia penal español en la actualidad está centrado en el castigo y su consecuencia, que es la pena ${ }^{3}$. Por medio del castigo, la sociedad puede creer que hay justicia, apaciguar los deseos de venganza que surgen ante la comisión del delito; el castigo tiene también una función intimidatoria para todos aquellos que pretendan quebrantar la ley. El resultado de este sistema es que no hay una verdadera respuesta a las necesidades de la víctima y la impartición de justicia queda desvirtuada ${ }^{4}$.

1 Podemos ver esta realidad en la producción legislativa proveniente de la Unión Europea (Directiva 2012/29/UE, que sustituye la Decisión marco 2001/220/JAI del Consejo; Directiva 2008/52/ $\mathrm{CE}$ ) y en el profuso desarrollo legislativo de la mediación familiar y civil en la legislación de las distintas comunidades autónomas que componen España. Unión Europea, Parlamento Europeo \& Consejo de la Unión Europea, Directiva 2012/29/UE del Parlamento Europeo y del Consejo, 25 de octubre de 2012, por la que se establecen normas mínimas sobre los derechos, el apoyo y la protección de las víctimas de delitos, y por la que se sustituye la Decisión marco 2001/220/ JAI del Consejo, 315 Diario Oficial de la Unión Europea, 14 de noviembre de 2012. Disponible en: http://eur-lex.europa.eu/legal-content/ES/TXT/?uri=CELEX:32012L0029. Unión Europea, Parlamento Europeo \& Consejo de la Unión Europea, Directiva 2008/52/CE del Parlamento Europeo y del Consejo de 21 de mayo de 2008 sobre ciertos aspectos de la mediación en asuntos civiles y mercantiles, L 136/3 Diario Oficial de la Unión Europea, DOUE, 24 de mayo de 2008. Disponible en: http://eur-lex.europa.eu/LexUriServ/LexUriServ.do?uri=OJ:L:2008:136:0003:0 008:Es:PDF

2 En este aspecto, encontramos por primera vez en España sentencias en materia penal que han contemplado transversalmente el procedimiento de mediación penal, como la sentencia AP Madrid, Sección 17, 621/2015 de 16 de septiembre (Recurso 6037/2013), el establecimiento de protocolos y convenios entre los órganos jurisdiccionales que ofrecen mediación, así como también la realización de estudios estadísticos que evidencian este crecimiento. Esta información está disponible en http://www.poderjudicial.es/cgpj/es/Temas/Mediacion. España, Audiencia Provincial de Madrid, Sentencia AP Madrid, Sección 17, 621/2015 de 16 de septiembre (Recurso 6037/2013), magistrado ponente María Jesús Coronado-Buitrago. Disponible en: http://www. poderjudicial.es/cgpj/es/Temas/Mediacion/Normativa-y-jurisprudencia/Sentencias/Materia -penal/Sentencia-AP-Madrid--Seccion-17--n--621-2015-de-16-de-septiembre--rec--6037-2013-

3 José Luis Segovia-Bernabé, Mediación penal comunitaria y justicia restaurativa. Una perspectiva ética y jurídica, en Mediación penal y penitenciaria. 10 años de camino, 17-56 (Fundación Ágape, Art\&Press, Madrid, 2010).

4 Karla Villarreal-Sotelo, La víctima, el victimario y la justicia restaurativa, 7 Rivista di Criminologia, Vittimologia e Sicurezza, 1, 43-57 (2013). Disponible en: http://www.vittimologia.it/ rivista/articolo_villarrealsotelo_2013-01.pdf 
Como consecuencia de esta manera de actuar, es necesaria la introducción de nuevas formas de actuar en justicia penal que permitan subsanar los errores y solucionar los conflictos que se producen, pero con el acento en la reparación del daño a la víctima y la reinserción o rehabilitación del delincuente ${ }^{5}$. Así empieza a tomar fuerza la mediación penal, que se basa en los presupuestos del paradigma de la justicia restaurativa.

La justicia restaurativa aboga por la rehabilitación de la paz social mediante el diálogo y el encuentro entre las personas afectadas y se vale de la mediación penal como instrumento para conseguir sus fines ${ }^{6}$. La mediación penal permite la disponibilidad del conflicto para las personas que lo sufren, la restitución de aquello que se ha malogrado con el delito y que el victimario tenga conciencia de sus actos.

Con una base teórica ya en marcha, para poder operar dentro del sistema de justicia es indispensable una regulación jurídica de esta materia. En este punto es necesario articular los instrumentos legales imprescindibles para darle viabilidad a la mediación penal. Desde las organizaciones internacionales como la ONU, que fueron pioneras en reconocer el papel de la mediación penal y comenzar a resaltar su importancia, se fueron estableciendo las bases para que luego fueran los órganos de la Comunidad Europea los que sintieran la necesidad de darle cabida a la mediación penal en la normativa comunitaria. Así, a partir de 2002, la Unión Europea permitió esta práctica y realizó el mandato legal de que cada país miembro comenzara a elaborar legislación para introducir la mediación penal en sus ordenamientos jurídicos. Como resultado de este mandato, los países de la Unión Europea tienen o deben tener una normativa que recoja la mediación penal y especifique cómo encaja esta experiencia en la práctica judicial.

\footnotetext{
5 Ramón Saéz-Valcárcel, La mediación penal, una metodología judicial para ocuparse de la reparación y de la resocialización, 2062 Boletín del Ministerio de Justicia, 1757-1770 (junio de 2008).

6 Silvia Barona-Vilar, Mediación penal: fundamento, fines y régimen jurídico (Tirant lo Blanch, Valencia, 2011).
} 
El estudio de estas leyes es fundamental para conocer cómo ha reaccionado cada uno de los países ante la mediación penal y por ello, ese ha sido nuestro objeto de estudio. Las leyes permiten esbozar un retrato de la realidad de la mediación penal, ya que estas van a ser la puerta de entrada a las prácticas de mediación penal en Europa. Es vital conocer lo que los demás países hacen para ver cómo pueden funcionar los demás con sistemas penales muy parecidos.

Ante la importancia de este estudio, era preciso gestionar su conocimiento de forma conjunta. Anteriormente, se han dado estudios que comprenden aspectos aislados de una o varias de estas leyes, sin llegar a establecer comparaciones o destacar aspectos decisivos de ellas. Con el objetivo de sistematizar el mayor número de aspectos de estas leyes, este trabajo intenta comprender de una forma más global el fenómeno de la mediación penal en Europa mediante la normativa vigente.

La metodología elegida para desarrollar este cometido fue cualitativa, para establecer un estudio exploratorio que permitiera sentar las primeras bases del estudio de normativa comparada. Con base en la técnica de obtención de datos del análisis documental de contenido y en la sistematización o categorización de las variables y las categorías de estudio, el resultado ha sido la utilización de un instrumento de obtención de datos basado en un análisis documental sistematizado por categorías. Para poder llevar a cabo toda la instrumentalización metodológica, el software especializado MaxQDA fue clave en el proceso, pues permite el tratamiento de datos o paquetes cualitativos. La antropología social y la sociología hacen valer frecuentemente este instrumento en sus investigaciones y en este estudio ha sido de extraordinaria importancia a la hora de agilizar el trabajo y el tratamiento sistematizado y científico de los datos.

Aunque ya se ha hecho alusión a que el principal objetivo de este estudio era conocer cómo se establece la mediación penal en los distintos instrumentos normativos de los países de la Unión Europea, es necesario especificar un poco más. Partiendo de lo anterior como objetivo general, los objetivos específicos de la 
investigación se centraron en señalar las cuestiones básicas de la legislación para comprender su contexto e implantación; en conocer la base teórica legal de la mediación penal en Europa y ver cuál es el reflejo de las consecuencias que recoge la legislación para la participación en la mediación penal.

Los principales resultados de este estudio revelan que la mediación penal es un instrumento de resolución de conflictos aún reciente en los países de la Unión Europea y que para que su implantación pueda alcanzar mayores efectos todavía es necesario un mayor desarrollo. La mediación penal se recoge tanto en códigos penales y procesales como en normativa autónoma a estos códigos, siendo estas las leyes más completas. Otro hallazgo significativo es que no hay una separación tajante entre delitos y faltas que impidan el acceso a la mediación en los primeros, aunque bastantes países sí ponen objeciones a que se pueda llevar a mediación determinado tipo de infracciones, por ejemplo en delitos cuya víctima es especialmente vulnerable, como en los delitos relacionados con la violencia de género o cuya víctima es menor de edad. Se parte de una base pobre en cuanto a teoría de la mediación y de la justicia restaurativa recogida en los textos; las consecuencias o efectos que se contemplan para la mediación son pocos y muy tasados.

Desde nuestro punto de vista, este trabajo de investigación sienta las bases o el punto de partida legislativo de la mediación penal en Europa, con una voluntad férrea de que se tome como base para su mejora. También existe la posibilidad de que países ajenos a la comunidad europea puedan tomar esta comparativa como herramienta para la propia implantación de normativa específica en mediación penal. Los estudios comparativos aportan riqueza cuando se potencian los puntos fuertes y se analizan y reestructuran los puntos más endebles. 


\section{FUNDAMENTOS TEÓRICOS}

Para poder acercarnos a la mediación penal es prioritario que lo hagamos desde el paradigma de la justicia restaurativa ${ }^{7}$. Esta principalmente, y a grandes rasgos, opta por poner al agresor $\mathrm{y}$ a la víctima en contacto y hacer que entre ellos, con ayuda de procedimientos restaurativos, puedan llegar a conclusiones satisfactorias y beneficiosas, en busca de la reparación del daño ocasionado como consecuencia del delito o la falta; este proceso de solución conflictual involucra la comunidad.

Las Naciones Unidas ajustan la definición de justicia restaurativa al sistema de justicia penal, al entenderla "como una respuesta evolucionada al crimen que respeta la dignidad y equidad de cada persona, construye comprensión y promueve armonía social a través de la 'sanación' de la víctima, infractor y comunidad"8. Sean como fueren la extensión y las notas elegidas para establecer la justicia restaurativa, esta supone apostar por valores como la no violencia, el principio de responsabilidad, la protección a las víctimas, el encuentro personal, el diálogo, la sanación de las heridas, la reparación del daño causado, la neutralización del miedo al diferente, la inserción social de los infractores, la paz social, la nivelación de asimetrías sociales y la recomposición de relaciones rotas ${ }^{9}$.

El paradigma que propone la justicia restaurativa es un planteamiento totalmente distinto y que pretende la complementariedad del sistema de justicia actual poniendo el acento en la reparación del daño.

7 Idea defendida por una gran cantidad de expertos, entre ellos destacan: Luis F. Gordillo-Santana, La justicia restaurativa y la mediación penal (Iustel, Madrid, 2007) y Julián Carlos RíosMartín, Justicia restaurativa y mediación penal. Una apuesta por el diálogo y la disminución de la violencia (2005-2008). Disponible en: http://www.poderjudicial.es/stfls/cgpj/Doc\%20 Temporales/DocsPublicacion/FICHERO/PONENCIA\%20JULIAN\%20RIOS_1.0.0.pdf. Este último autor ha realizado varios estudios en el seno de la organización judicial.

8 Virginia Domingo de la Fuente, Contexto teórico-práctico de la justicia restaurativa en Europa con especial atención a España, 4 Revista Criminología y Justicia, 70-83 (2012). Disponible en: http://dialnet.unirioja.es/servlet/articulo?codigo $=4063084$

9 José Luis Segovia-Bernabé, Mediación penal comunitaria y justicia restaurativa. Una perspectiva ética y jurídica, en Mediación penal y penitenciaria. 10 años de camino, 17-56 (Fundación Ágape, Art\&Press, Madrid, 2010). 
La mediación es la principal herramienta de la justicia restaurativa y surge como un puente necesario que une a personas que están vinculadas por el daño penal. La mediación, como un juego entre las definiciones que nos brindan Jay Folberg y Alison Taylor, y Christopher Moore ${ }^{10}$.

Aplicada al mundo penal, podemos tener en cuenta la definición normativa de mediación, del Comité de Ministros del Consejo de Europa en su Recomendación R(99)1911.

Para obtener una mayor comprensión del fenómeno de la mediación es necesario conocer cuáles son sus notas características y cómo influyen en el desarrollo del proceso. Con este fin se ha realizado la tabla 1, para expresar de manera esquemática y simplificada por una parte los principios característicos de la mediación en un sentido general ${ }^{12}$ aplicados al ámbito penal, en la columna izquierda, y los principios específicos de la mediación penal que únicamente son relevantes en este ámbito, en la columna derecha.

10 "La mediación es: un procedimiento que resuelve el conflicto entre dos con un acuerdo justo y legal, obtenido de un diálogo, mantenido de forma voluntaria, moderado por un mediador imparcial y neutral, provisto de autoridad moral y privado de potestad coercitiva". Francisco de Paula Puy-Muñoz, La expresión "mediación jurídica": un análisis tópico, en Mediación y solución de conflicto. Habilidades para una necesidad emergente, 21-36, 22-33 (Helena SoletoMuñoz \& Milagros María Otero-Parga, coords., Tecnos, Madrid, 2007). Jay Folberg \& Alison Taylor, Mediation: A Comprehensive Guide to Resolving Conflicts without Litigation (Wiley, Jossey Bass, San Francisco, 1984). Christopher W. Moore, Natural Resources Conflict Management (Accord Associates, Boulder, Colorado, 1982). Christopher W. Moore, The Mediation Process: Practical Strategies for Resolving Conflict (Jossey Bass Wiley, San Francisco, 2003).

11 Se entiende por mediación aplicada al campo penal: "cualquier proceso que permite a la víctima y al reo participar activamente, si lo consintieran libremente, en la solución de las dificultades ocasionadas por el delito con la ayuda de un tercero independiente (el mediador)". Unión Europea, Comité de Ministros del Consejo de Europa, Recomendación R(99)19, 15 de septiembre de 1999, apéndice, definición. Disponible en: https://search.coe.int/cm/Pages/result_details. aspx?ObjectID $=090000168062 \mathrm{e} 02 \mathrm{~b}$

12 Se habla del sentido general, porque estos principios se aplican a cualquier clase de proceso de mediación, con independencia del ámbito de actuación. También tienen vigencia para la mediación penal. 


\section{Tabla 1}

Principios de mediación

\begin{tabular}{|c|c|}
\hline \multicolumn{2}{|c|}{ Principios de mediación } \\
\hline Generales & Específicos de mediación penal \\
\hline $\begin{array}{l}\text { Voluntariedad } \\
\text { La participación en el proceso de } \\
\text { mediación penal es voluntaria. } \\
\text { Esta tiene que ser acti- } \\
\text { va, libre y consciente. } \\
\text { Tiene que haber una informa- } \\
\text { ción pertinente para que las } \\
\text { partes decidan permanecer } \\
\text { en el proceso de mediación. }\end{array}$ & $\begin{array}{l}\text { Complementariedad } \\
\text { Mediación penal no signi- } \\
\text { fica un mecanismo ajeno al } \\
\text { sistema de justicia penal. } \\
\text { La mediación penal se aco- } \\
\text { pla como una estrategia más, } \\
\text { porque necesita de la jus- } \\
\text { ticia penal como sustento } \\
\text { para poder desempeñarse. }\end{array}$ \\
\hline $\begin{array}{l}\text { Confidencialidad } \\
\text { De la mediación entre las par- } \\
\text { tes no puede salir ningún dato; } \\
\text { únicamente se puede conocer } \\
\text { el acta de acuerdo o el infor- } \\
\text { me del equipo de mediación. } \\
\text { El principio a la presunción de } \\
\text { inocencia del acusado queda } \\
\text { indemne ya que lo que se expon- } \\
\text { ga en el proceso no va contra } \\
\text { las partes en sentido incrimina- } \\
\text { torio y, si se decide abandonar } \\
\text { el proceso penal, continúa con } \\
\text { todo el sistema probatorio. }\end{array}$ & $\begin{array}{l}\text { Oficialidad } \\
\text { Ligado al principio de } \\
\text { complementariedad. } \\
\text { El proceso de mediación pe- } \\
\text { nal no es independiente del } \\
\text { procedimiento judicial. } \\
\text { Consecuencia de este principio: } \\
\text { la mediación penal únicamen- } \\
\text { te puede ser intrajudicial en } \\
\text { cualquiera de las fases en las } \\
\text { que el litigio se encuentre, por- } \\
\text { que estamos hablando de un } \\
\text { derecho de carácter público. }\end{array}$ \\
\hline $\begin{array}{l}\text { Flexibilidad } \\
\text { La mediación penal puede reali- } \\
\text { zarse de forma abierta en cuanto } \\
\text { a la forma de llevarse a cabo y } \\
\text { también en cuanto a los plazos. }\end{array}$ & $\begin{array}{l}\text { Gratuidad } \\
\text { La mediación penal tiene que ser } \\
\text { gratuita para ambas partes, por } \\
\text { razones de no discriminación y } \\
\text { porque la jurisdicción penal se } \\
\text { encarga del derecho público. }\end{array}$ \\
\hline
\end{tabular}

Fuente: elaboración propia

Una vez enunciadas las características de esta práctica, también conviene conocer cuál es su ubicación legal en los instrumentos legales internacionales y comunitarios. Al plantear un 
estudio de la normativa que sustenta la mediación penal, hay que hacer dos distinciones: la primera, en cuanto a la obligatoriedad de los instrumentos legales y la segunda, en atención a la procedencia de estas normas, es decir, en atención al órgano emitente.

La normativa en materia de mediación penal no es homogénea ni en su creación ni en la aplicación que hacen los distintos Estados. Desde instancias internacionales, organizaciones como las Naciones Unidas o el Consejo de Europa han ido generando un conjunto de normas ${ }^{13}$ que dotan de sentido a la práctica de la mediación penal pero no tienen un carácter vinculante para los Estados. A pesar de ello, son de vital importancia, debido a que proporcionan la esencia de la justicia restaurativa y la práctica de la mediación en el ámbito penal, aunque no tienen fuerza de ley para los Estados, sino que marcan las directrices a seguir.

Ahora bien, ya con carácter vinculante y provenientes del Derecho Comunitario, encontramos la primera norma que obliga a los Estados a establecer normativa que dé cabida a la mediación en el ámbito penal: la Decisión Marco 2001/220/JAI del Consejo de la Unión Europea ${ }^{14}$, relativa al estatuto de la

13 A partir del VI Congreso de la ONU, celebrado en Caracas en 1980 y el VII Congreso de la ONU, celebrado en Milán en agosto-septiembre de 1985, se aprobaron distintas resoluciones y declaraciones. Organización de Naciones Unidas, ONU, Asamblea General, Declaración sobre los principios fundamentales de justicia para las víctimas de delitos y del abuso de poder, A/ RES 40/34, Resolución 40/34, 29 de noviembre de 1985. Disponible en: http://www.ohchr.org/ $\mathrm{SP} /$ ProfessionalInterest/Pages/VictimsOfCrimeAndAbuseOfPower.aspx, https://www.unodc. org/pdf/criminal_justice/Compendium_UN_Standards_and_Norms_CP_and_CJ_Spanish. pdf. Organización de Naciones Unidas, $\overline{O N N U}^{-}$Asamblea General, Reglas Mínimas de las Naciones Unidas sobre las medidas no privativas de libertad, Reglas de Tokio, adoptadas por la Asamblea General en su resolución 45/110, 14 de diciembre de 1990. Disponible en: http://www. hchr.org.co/documentoseinformes/documentos/carceles/1_Universales/B\%E1sicos/6_Preven cion_delito_tratamiento_delinc/1161_Reglas_m\%EDn_NU_medidas_no_priva_libert.pdf, https://www.unodc.org/pdf/criminal_justice/Compendium_UN_Standards_and_Norms CP_and_CJ_Spanish.pdf. Organización de Naciones Unidas, ONU, Consejo Económico y Social, ECOSOC, Elaboración y aplicación de medidas de mediación y justicia restaurativa en materia de justicia penal, Resolución 1999/26, 28 de julio de 1999. Disponible en: https:// www.unodc.org/documents/commissions/CCPCJ/Crime_Resolutions/1990-1999/1999/ECO SOC/Resolution_1999-26.pdf. Organización de Naciones Unidas, ONU, Consejo Económico y Social, ECOSOC, Resolución 2000/14, 27 julio de 2000. Disponible en: https://www.unodc. org/documents/commissions/CCPCJ/Crime_Resolutions/2000-2009/2000/ECOSOC/Reso lution_2000-14.pdf. Organización de Nacionés Unidas, ONU, Consejo Económico y Social, ECOSOC, Declaración del Consejo Económico y Social de la ONU, 18 de abril de 2002.

14 Unión Europea, Consejo de la Unión Europea, Decisión marco del Consejo de 15 de marzo de 2001 relativa al estatuto de la víctima en el proceso penal (2001), 2001/220/JAI, L 82/1 Diario 
víctima en el proceso penal. Esta norma sustentó la mediación penal comunitariamente a falta de que los Estados miembros articulasen normas estatales que den apoyo a la mediación penal en los ordenamientos jurídicos. Fue una norma de derecho necesario, es decir, los destinatarios estaban obligados a cumplirla porque es vinculante, pero cada uno de ellos podía hacerlo de acuerdo a las características de su normativa nacional. Algunos estados no han cumplido el mandato de la Decisión Marco ${ }^{15}$, sobrepasando sobremanera el plazo establecido en la ley, como es el caso español.

Debido al tiempo transcurrido de este criterio, se emitió otra norma comunitaria que regula de una forma más específica las materias enunciadas en la Decisión Marco (2001/220/JAI), como los derechos de las víctimas, el apoyo y la protección necesaria que se les ha de dar después de haber sufrido un delito; esta es la Directiva 2012/29/UE del Parlamento Europeo y del Consejo ${ }^{16}$.

De la existencia de estas dos fuentes legales de extrema importancia en el ámbito europeo, la situación normativa de la mediación penal en el derecho comunitario queda establecida como muestra la gráfica 1 :

Oficial de las Comunidades Europeas, 22 de marzo de 2001. Disponible en: http://eur-lex. europa.eu/legal-content/ES/ALL/?uri=CELEX:32001F0220

15 Artículo 17: “Los Estados miembros pondrán en vigor las disposiciones legales, reglamentarias y administrativas necesarias para dar cumplimiento a lo estipulado en la presente Decisión marco: en lo que se refiere al artículo 10, a más tardar el 22 de marzo de 2006 [...]”. Unión Europea, Consejo de la Unión Europea, Decisión marco del Consejo de 15 de marzo de 2001 relativa al estatuto de la víctima en el proceso penal (2001), 2001/220/JAI, L 82/1 Diario Oficial de las Comunidades Europeas, 22 de marzo de 2001. Disponible en: http://eur-lex.europa.eu/ legal-content/ES/ALL/?uri=CELEX:32001F0220

16 Unión Europea, Parlamento Europeo \& Consejo de la Unión Europea, Directiva 2012/29/UE del Parlamento Europeo y del Consejo, 25 de octubre de 2012, por la que se establecen normas mínimas sobre los derechos, el apoyo y la protección de las víctimas de delitos, y por la que se sustituye la Decisión marco 2001/220/JAI del Consejo, 315 Diario Oficial de la Unión Europea, 14 de noviembre de 2012. Disponible en: http://eur-lex.europa.eu/legal-content/ES/ TXT/?uri=CELEX:32012L0029 
Gráfica 1

Progresión legislativa de la mediación penal en la Unión Europea

Legislación proveniente de la ONU

Legislación proveniente del Consejo de Europa
Leyes de

Normativa de la Unión

Europea

- Decisión Marco

(2001/220/JAI)

- Directiva

2012/29/UE mediación

de cada

país de la

Unión

Europea

Debido a la obligación de incorporar normativa específica en mediación penal por la normativa vinculante de la Unión Europea, la mayoría de los estados miembros ha interpretado todos estos instrumentos legislativos y los ha incorporado a su normativa interna en función de sus necesidades, potencialidades y debilidades. Como consecuencia última de esta obligación de legislar, el resultado ha sido una variedad de normas de mediación penal. En esto se ha centrado la siguiente investigación, en una comparativa entre cada una de las regulaciones que han realizado los países de la UE a raíz de la necesidad de recoger en las leyes la mediación penal.

\section{MetodologíA}

La metodología para esta investigación se escogió en función del objetivo principal y de los objetivos específicos creados. Como objetivo principal, se establece poder conocer la normativa en 
mediación penal de los países de la Unión Europea. Esta premisa básica se desarrolla en tres objetivos específicos de investigación: - Identificar las disposiciones generales y las cuestiones básicas.

- Determinar las nociones teóricas de la justicia restaurativa y la mediación penal que componen los textos legales.

- Conocer cuáles son los efectos de participar en un proceso de mediación que tienen reflejo en la legislación en la materia.

Para facilitar la comprensión del esquema de los objetivos de investigación, la tabla 2 pormenoriza las variables, categorías y subcategorías de análisis. Estos dos últimos elementos fueron una de las herramientas principales que permitieron la sistematización de la investigación. 

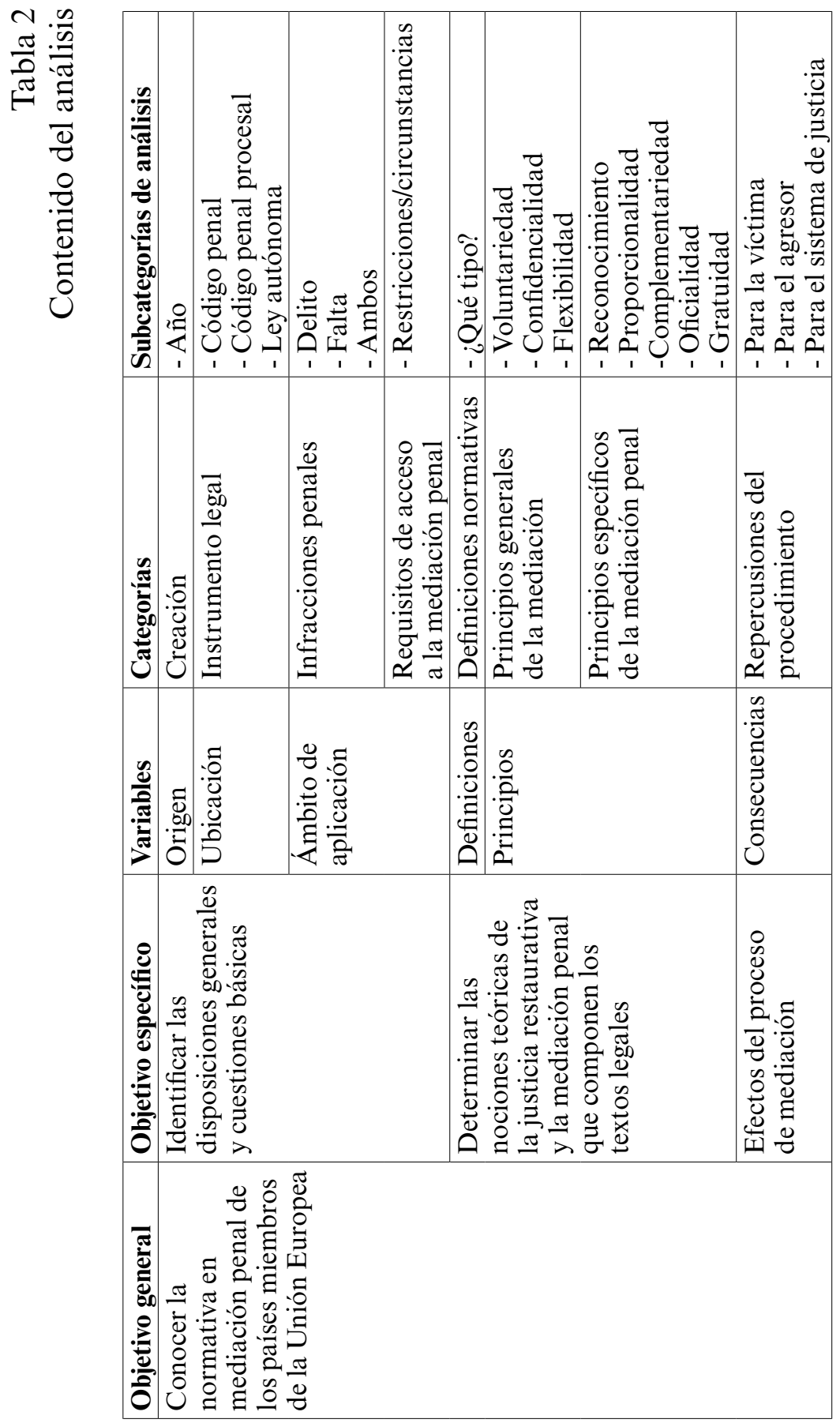

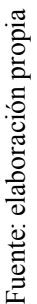


Una vez establecidos los objetivos de la investigación, fue necesaria una descripción de las variables de análisis. Estas variables son las siguientes:

Tabla 3

Variables de análisis

\begin{tabular}{|l|l|}
\hline \multicolumn{1}{|c|}{ Variables } & \multicolumn{1}{c|}{ Explicación } \\
\hline Origen & $\begin{array}{l}\text { Fecha de creación o de introducción de la mediación } \\
\text { en el cuerpo normativo penal de los distintos } \\
\text { países seleccionados para conocer la antigüedad } \\
\text { y desarrollo de la implantación jurídica. }\end{array}$ \\
\hline Ubicación & $\begin{array}{l}\text { El espacio en la normativa de cada uno de los países } \\
\text { donde está ubicada la mediación penal, diferenciando } \\
\text { entre los distintos instrumentos legales posibles, } \\
\text { por la necesidad de conocer cuál es la tipología } \\
\text { legal del texto, si es más general o específico. }\end{array}$ \\
\hline $\begin{array}{l}\text { Ámbito de } \\
\text { aplicación }\end{array}$ & $\begin{array}{l}\text { Ámbito de actuación de la mediación penal en } \\
\text { los distintos países, es decir, si la mediación se } \\
\text { aplica a todo tipo de infracciones penales y así } \\
\text { determinar si es un número cerrado de supuestos, } \\
\text { que pueden ser delitos, faltas o ambos; o si, por } \\
\text { el contrario, no hay establecido un sistema de } \\
\text { numerus clausus que restrinja la intervención. }\end{array}$ \\
\hline Definiciones & $\begin{array}{l}\text { Definiciones normativas de justicia restaurativa } \\
\text { y del instrumento de la mediación penal } \\
\text { que puedan guiar la intervención para ver } \\
\text { cómo se plasman en los textos legales. }\end{array}$ \\
\hline Principios & $\begin{array}{l}\text { Principios de la justicia restaurativa y de la mediación } \\
\text { penal que tienen reflejo y de qué manera lo tienen en los } \\
\text { instrumentos normativos que legitiman la mediación } \\
\text { penal en los países europeos, es decir, cómo se plasman } \\
\text { y cómo condicionan la realización de la mediación } \\
\text { penal, haciendo una distinción entre los que configuran } \\
\text { en el mapa de la mediación en general y los que se } \\
\text { aplican específicamente a la mediación penal con el fin } \\
\text { de conocer la base teórica sobre la que se asientan. }\end{array}$ \\
\hline Consecuencias & $\begin{array}{l}\text { Repercusiones de un proceso de mediación penal } \\
\text { para determinar cómo influyen a los actores } \\
\text { del proceso penal; o si se alude a que el proceso } \\
\text { de mediación en general modifica el entorno } \\
\text { del sistema judicial o a las personas para } \\
\text { determinar el impacto de la mediación penal. }\end{array}$ \\
\hline and
\end{tabular}

Fuente: elaboración propia 
En los últimos años, la mediación ha tenido una buena acogida en diversos ámbitos; ya están comenzando a darse estudios que investigan sus características, pero no dejamos de estar ante un fenómeno poco estudiado y que despierta muchas dudas.

Debido a estas características, el diseño de la investigación ha de ser exploratorio, porque su rasgo principal es que tiene una finalidad exploratoria de fenómenos desconocidos o poco estudiados. Esta profundidad es necesaria para obtener información que permita familiarizarnos con el objeto de estudio y llevar a cabo una investigación más completa en un futuro ${ }^{17}$.

El enfoque metodológico elegido para abordar este tema fue el cualitativo con el fin de que se facilitase la "reconstrucción" de la realidad que permitiera al investigador interpretar, es decir, "encontrar sentido a los fenómenos en función de los significados que las personas les otorgamos"18. Este enfoque nos dejó enriquecer y profundizar en la materia, a partir de una lógica de investigación inductiva sin llegar a la medición numérica.

Como herramienta o técnica para operar con la metodología cualitativa escogida, el análisis documental de contenido fue la mejor opción. Jaime Andréu-Abela establece que esta técnica "se basa en la lectura (textual o visual) como instrumento de recogida de información, lectura que a diferencia de la lectura común debe realizarse siguiendo el método científico, es decir, debe ser sistemática, objetiva, replicable y válida”. Esta técnica es semejante a cualquier otra técnica de recolección de datos de investigación social, pero con la ventaja añadida de que permite, además de la observación objetiva, la interpretación de los datos por parte del investigador ${ }^{19}$. La producción, trata-

17 Roberto Hernández-Sampieri, Carlos Fernández-Collado \& María del Pilar Baptista-Lucio, Metodología de la investigación (McGraw-Hill, México, 2010). Disponible en: https://www.esup. edu.pe/descargas/dep_investigacion/Metodologia $\% 20 \mathrm{de} \% 201 \mathrm{a} \% 20$ investigaci $\% \mathrm{C} 3 \% \mathrm{~B} 3 \mathrm{n} \% 20$ 5 ta\% 20 Edici $\% \mathrm{C} 3 \% \mathrm{~B} 3 \mathrm{n}$.pdf

18 Roberto Hernández-Sampieri, Carlos Fernández-Collado \& María del Pilar BaptistaLucio, Metodología de la investigación, 10 (McGraw-Hill, México, 2010). Disponible en: https://www.esup.edu.pe/descargas/dep_investigacion/Metodologia\%20de $\% 201 \mathrm{a} \% 20$ investigaci\%C3\%B3n\%205ta\%20Edici\%C3\%B3n.pdf

19 Jaime Andréu-Abela, Las técnicas de análisis de contenido: una revisión actualizada, 1-34, 2 (Centro de Estudios Andaluces, Junta de Andalucía, Working paper S200103, 2001). Disponible en: http://public.centrodeestudiosandaluces.es/pdfs/S200103.pdf 
miento u organización, recuperación, diseminación y uso de la información, mediante procedimientos de naturaleza analíticosintética, posibilitan crear una nueva producción documental (la investigación), que puede ser la base para el mismo recorrido de análisis que aloje la posibilidad de seguir ampliando el conocimiento sobre este tema ${ }^{20}$.

Una vez se escogió la técnica de análisis, fue necesario perfilar el instrumento para obtener los datos. Para desarrollar el análisis, se hizo una codificación de categorías de investigación que después tendrían que ser buscadas en los textos; por eso, el instrumento de obtención de datos fue un análisis documental sistematizado por categorías. La categorización o división en categorías de estudio es una operación de clasificación de los elementos definidores que determinan un conjunto, para poder diferenciarlos de otros, realizados bajo algún criterio que establece el investigador ${ }^{21}$. Para poder realizarla, hay que llevar a cabo dos fases: la primera fase es inventariar los elementos de análisis y la segunda consiste en clasificar los elementos que corresponden a las categorías y subcategorías para conseguir una organización que les dé sentido a los mensajes.

En esta segunda fase de la categorización entró en juego el instrumento con el que se organizó toda la información de la investigación: el software MAXqda o MAXQDA en su versión de $2011^{22}$ que permite el trabajo con paquetes de datos cualitativos (CAQDAS).

El esquema de la metodología de investigación se aplicó al objeto de la investigación: los documentos seleccionados para el análisis. Estos documentos fueron elegidos con el criterio de ser instrumentos legales en los que la mediación en el ámbito penal

20 José Augusto Chaves Guimarães, João Batista Ernesto de Moraes \& Maura Duarte Moreira Guarido, Análisis documental de contenido de textos narrativos: bases epistemológicas y perspectivas metodológicas, 1 Ibersid, Revista de Sistemas de Información y Documentación, 93-99, 94 (2007). Disponible en: http://www.ibersid.eu/ojs/index.php/ibersid/article/view/3267/3028

21 Jaime Andréu-Abela, Las técnicas de análisis de contenido: una revisión actualizada, 1-34 (Centro de Estudios Andaluces, Junta de Andalucía, Working paper S200103, 2001). Disponible en: http://public.centrodeestudiosandaluces.es/pdfs/S200103.pdf

22 Versión del programa demo, que permite unos 30 días de muestra gratuita durante los cuales se puede trabajar con el programa. Disponible en: http://www.maxqda.com/downloads/demo 
tuviera cabida, con independencia del tipo de regulación penal que contuviera y fuera cual fuera su contenido. El nexo de todos ellos es la temática en mediación penal. Se trata de documentos administrativos de carácter legal, con independencia de su rango legislativo, que tienen la consideración de documentos obtenidos de fuentes secundarias. Todos ellos encontrados en internet y traducidos al español desde la lengua original. De la búsqueda, los documentos seleccionados corresponden a los siguientes países y son los siguientes (con información complementaria que es necesaria para su localización en los instrumentos de publicación de leyes):

Tabla 4

Legislación empleada para el análisis en función del país de origen

\begin{tabular}{|l|l|}
\hline \multicolumn{1}{|c|}{ País } & \multicolumn{1}{c|}{ Texto legal } \\
\hline Alemania & $\begin{array}{l}\text { Código Penal (StGB), en la versión promulgada el } \\
\text { 13 de noviembre de 1998, Boletín Oficial Federal } \\
\text { (Bundesgesetzblatt) I, 3322, modificado en último } \\
\text { lugar por el artículo 3 de la Ley de 2 de octubre } \\
\text { de 2009, Boletín Oficial Federal I, 3214. }\end{array}$ \\
\cline { 2 - 2 } & $\begin{array}{l}\text { Código de Procedimiento Penal (StPO), en la versión } \\
\text { publicada el 7 de abril de 1987, Boletín Oficial Federal } \\
\text { (Bundesgesetzblatt) Parte I. 1074, 1319, modificado en } \\
\text { último lugar por el artículo 3 de la Ley de 23 de abril } \\
\text { de 2014 (Gaceta de Leyes Federales Parte I, 410). }\end{array}$ \\
\hline Austria & $\begin{array}{l}\text { Código Penal, modificado el 4 de noviembre de 2013. Ley } \\
\text { Federal de 23 de enero de 1974 relativa amenazó con } \\
\text { acciones judiciales de castigo (Código Penal - StGB). } \\
\text { StF: Gaceta de Leyes Federales 60/1974 (NR: GP XIII } \\
\text { RV 30 u. 1000 AB 959 y 1011 S. 84 y 98 BR: 326). }\end{array}$ \\
\cline { 2 - 3 } & $\begin{array}{l}\text { Código de Procedimiento Penal de 1975, modificado el 5 de } \\
\text { marzo de 2015. StF: Gaceta de Leyes Federales 631/1975. }\end{array}$ \\
\hline Bélgica & $\begin{array}{l}\text { Código de Procedimiento Judicial-penal (Code Judiciaire). } \\
\text { Séptima parte: mediación (arts. 1724-1737). Insertado } \\
\text { L 2005-02-21/36, Art. 8-21; vigencia: 30-09-2005, } \\
\text { excepto s. 11; en vigencia: 22 de marzo de 2005. }\end{array}$ \\
\hline
\end{tabular}




\begin{tabular}{|l|l|}
\hline \multicolumn{1}{|c|}{ País } & \multicolumn{1}{c|}{ Texto legal } \\
\hline Finlandia & $\begin{array}{l}\text { Ley de conciliación en casos civiles y penales } \\
\text { (1015/2005), Ministerio de Asuntos Sociales y Salud. }\end{array}$ \\
\hline Francia & $\begin{array}{l}\text { Código de Procedimiento Penal. Ley de 4 de } \\
\text { enero de 1993. Version consolidée du code au } \\
\text { 29 décembre 2014. Edition: 2015-01-04. }\end{array}$ \\
\cline { 2 - 3 } & $\begin{array}{l}\text { Código Penal (última modificación: 28 de marzo de } \\
\text { 2015). Versión en vigor desde el 27 de abril de 2015. }\end{array}$ \\
\hline Hungría & $\begin{array}{l}\text { Ley CXXIII de 2006 aplicable en materia } \\
\text { penal, actividades de intermediación. }\end{array}$ \\
\hline & $\begin{array}{l}\text { Código Penal de 2012 de la República de Hungría. } \\
\text { Ley IV de 1978, reformada en 2012. }\end{array}$ \\
\cline { 2 - 3 } & $\begin{array}{l}\text { Ley XIX de 1998 del Código de Procedimiento } \\
\text { Criminal, 18 de agosto de 2005. Criminal } \\
\text { Procedure Code of the Republic of Hungary. }\end{array}$ \\
\hline Italia & $\begin{array}{l}\text { Decreto Legislativo 274, 28 de agosto de 2000. } \\
\text { Disposiciones sobre la jurisdicción penal del juez de } \\
\text { paz, de conformidad con el artículo 14 de la Ley 468, 24 } \\
\text { de noviembre de 1999. Publicado en la Gaceta Oficial } \\
\text { 234, 6 de octubre 2000 - suplemento ordinario. 166. }\end{array}$ \\
\hline Luxemburgo & $\begin{array}{l}\text { Reglamento del Gran Ducado, 25 de junio de 2012, que } \\
\text { fija los procedimientos de aprobación de las funciones } \\
\text { del Defensor del Pueblo legal y la familia, el programa de } \\
\text { formación específica en mediación y la celebración de una } \\
\text { reunión de información libre (Formación en mediación) }\end{array}$ \\
\hline $\begin{array}{l}\text { Reglamento del Gran Ducado, 24 de julio de 2011, que } \\
\text { modifica el Reglamento del Gran Ducado, 21 de junio } \\
\text { de 1993, relativa al procedimiento de mediación previsto } \\
\text { en el artículo 69 del Código de Seguridad Social. }\end{array}$ \\
\hline
\end{tabular}




\begin{tabular}{|l|l|}
\hline \multicolumn{1}{|c|}{ País } & \multicolumn{1}{c|}{ Texto legal } \\
\hline Polonia & $\begin{array}{l}\text { Código Ético de los mediadores. } \text { Regla adoptada } \\
\text { por el Consejo Social de Métodos Alternativos de } \\
\text { Resolución de Conflicto y Resolución de Disputas en el } \\
\text { Ministerio de Justicia. Varsovia, 19 de mayo de 2008. }\end{array}$ \\
\cline { 2 - 3 } & $\begin{array}{l}\text { Código Penal, 6 de junio de 1997 (Dz. } \\
\text { U., 2 de agosto de 1997). }\end{array}$ \\
\cline { 2 - 3 } & Código de Procedimiento Penal. Ley de 6 de junio de 1997. \\
\cline { 2 - 3 } & $\begin{array}{l}\text { Normas para la formación de los mediadores, regla } \\
\text { adoptada por el Consejo Social de Métodos Alternativos } \\
\text { de Resolución de Conflicto y Resolución de Disputas } \\
\text { en el Ministerio de Justicia, 29 de octubre de 2007. }\end{array}$ \\
\cline { 2 - 3 } & $\begin{array}{l}\text { Ley sobre la conducta de la mediación en materia } \\
\text { penal, 13 de junio de 2003. Gaceta Oficial 108, 7109. } \\
\text { Ministro Rozporzñdzenie Sprawiedliwoâci. }\end{array}$ \\
\hline Portugal & $\begin{array}{l}\text { Ley 21/2007, 12 de junio, que crea un plan de } \\
\text { mediación, de conformidad con el artículo 10 de la } \\
\text { Decisión marco 2001/220/JAI del Consejo, de 15 de } \\
\text { marzo sobre el estatuto de la víctima en el proceso } \\
\text { penal. Promulgada el 30 de mayo de 2007. }\end{array}$ \\
\hline República & $\begin{array}{l}\text { Ley 359/1999, recopilación, sobre la protección } \\
\text { infantil (Ley de Libertad Vigilada y Mediación). }\end{array}$ \\
\hline
\end{tabular}

Fuente: elaboración propia

\section{RESULTADOS}

Como resultado de esta investigación, se ha obtenido la siguiente información que se presenta ordenada por categorías de análisis.

Categoría 1: Creación

El análisis de los resultados permite ver que la incorporación de la mediación penal al cuerpo de leyes de los países estudiados es relativamente reciente, en su mayor parte después del año 2000, sobre todo cuando está recogida en normas de carácter autónomo al código penal o procesal penal. Cuando la mención se realiza en textos legislativos - como pueden ser códigos penales o procesales penales-, se adelanta en el tiempo por la 
creación misma de las leyes. Por ejemplo, la ley de mediación penal de Portugal, que es autónoma, es del 12 de junio de 2007; en 2006, Finlandia y Rumania se suman a este esfuerzo; mientras Francia recoge la mediación penal en los códigos penales y procesales en 1993.

Categoría 2: Instrumento legal

La mayoría de los textos que hacían mención y recogían la mediación penal han sido leyes autónomas al Código Penal o al Código Procesal Penal (Rumania, Suecia, República Checa, Luxemburgo, Finlandia, Hungría, Portugal y Polonia), es decir, mayoritariamente estaban recogidas en instrumentos legales específicos para ella. También ha habido un alto porcentaje de instrumentos legales que no llegaban a la categoría de ley, pero sí tenían carácter oficial por el órgano emitente que recogían de manera más específicas los detalles de la mediación penal (Luxemburgo e Italia). La Gráfica 2 muestra la distribución de la categoría Instrumento legal en los veintiún textos analizados:

Gráfica 2 Instrumento legal

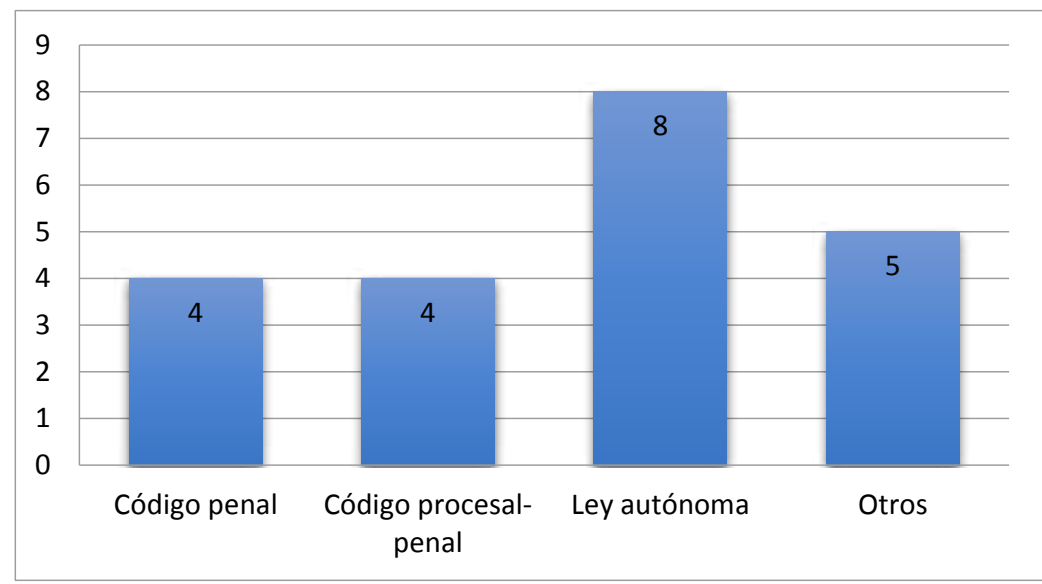

Fuente: elaboración propia 
Categoría 3: Infracciones penales

Del examen de esta categoría, encontramos que no hay una separación tangible entre los delitos y las faltas. En los textos estudiados se hace alusión al alcance de la mediación penal de múltiples maneras, ya sea por ilícitos específicos o por categorías procesales ${ }^{23}$. En general, los textos se refieren a delitos poco graves o de naturaleza menor en la mayoría de los casos y en otros a delitos, dejando sin ningún resultado la subcategoría faltas.

Una de las evidencias está en la sección 29 del Código Penal de Hungría que fija el catálogo para la mediación penal en "delito menor contra la vida, la integridad física o la salud, contra la libertad personal, contra los derechos fundamentales y la dignidad humanas, cualquier delito de tráfico, delitos contra la propiedad o contra los derechos de propiedad intelectual, o cualquier delito punible con pena de prisión de hasta tres años..." o la Ley 21/2007 de mediación penal de Portugal, que en su artículo 2 dice: "puede tener lugar en los procesos por delitos por los que el procedimiento depende de queja o acusación particular. (2) La mediación en el proceso penal solo puede tener lugar en los procesos por delitos que depende únicamente de queja en el caso de los delitos contra las personas o de la delincuencia contra la propiedad".

Categoría 4: Requisitos de acceso a la mediación

Con respecto al análisis de esta categoría hay que hacer su examen en dos vertientes: la de condiciones necesarias para poder empezar la mediación, que normalmente tienen que cumplirse en el acusado y, por otra parte, las restricciones estrictas tasadas en la ley que impiden llevar a cabo la mediación en una serie de supuestos. Son mayoría los países que establecen un numerus clausus de supuestos en los que la mediación penal

23 Como los ilícitos perseguibles a instancia de parte, es decir, que sea necesaria la denuncia o la acción penal por parte de la persona afectada; o simplemente aluden a características generales que deben valorar las personas encargadas. 
no va a poder llevarse a cabo según el tipo de delito del que se trate. Las infracciones que pueden impedir el acceso al proceso de mediación penal se representan en la gráfica 3 , que alude al número de normas en los que es posible encontrarlas:

Gráfica 3

Impedimentos para llevar a cabo el proceso de mediación por tipo de infracción

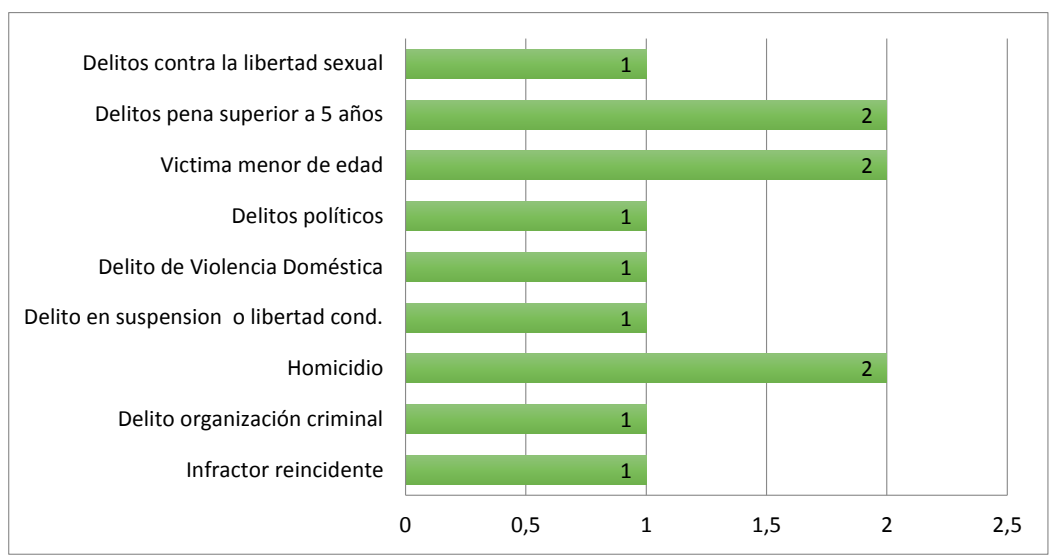

Fuente: elaboración propia

Categoría 5: Definiciones normativas

Los resultados en esta categoría son escasos, ya que solo seis de los veintitrés textos (6/23), es decir, de seis países, hacen referencia a alguna definición relacionada con el proceso de mediación, ya sea la definición de mediación, de justicia restaurativa, o del mediador y sus funciones. La mayoría de ellas son bastante completas y aluden a los principios de la mediación en un sentido general y con fines destinados a la reparación del daño. La distribución de las definiciones por temática se plasma en la gráfica 4: 
Gráfica 4

Definiciones normativas

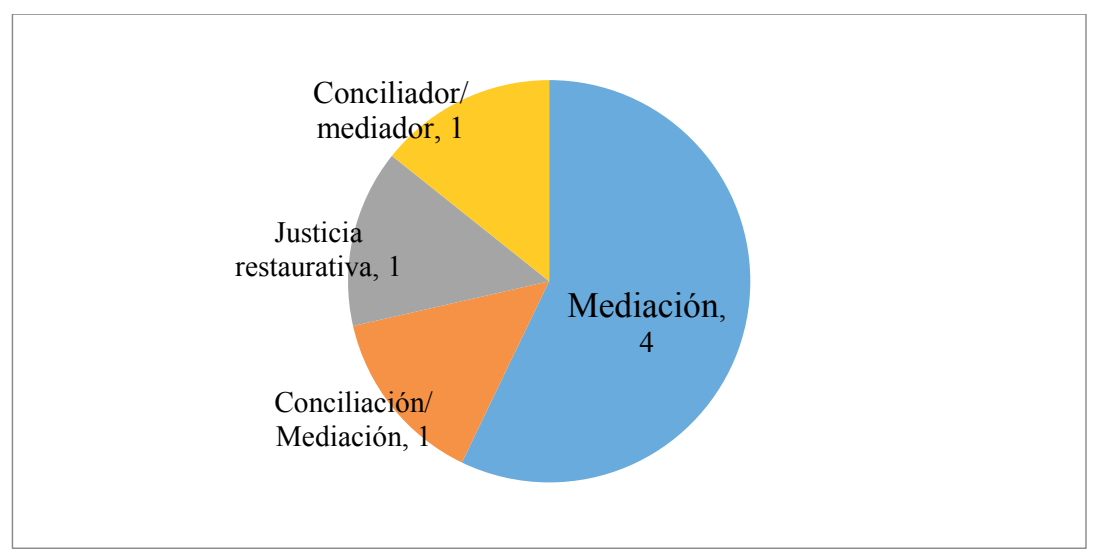

Fuente: elaboración propia

En estas definiciones, resalta la de Portugal, una de las más completas, que en su artículo 4.1 de la Ley de Mediación penal declara: "La mediación es un proceso informal y flexible, llevada a cabo por un tercero imparcial, el mediador, que promueve el acercamiento entre el acusado y la víctima y los apoya en un intento de encontrar activamente un acuerdo para permitir la reparación de daños causados por el acto ilegal y contribuir a la restauración de la paz social".

Categoría 6: Principios generales de la mediación

Los principios generales de la mediación (voluntariedad, confidencialidad, flexibilidad y otros) están muy presentes en cada uno de los textos analizados. La distribución de las referencias a ellos encontradas en los documentos de análisis fue la siguiente: 
Tabla 5

Distribución de los principios generales de la mediación

\begin{tabular}{|l|c|}
\hline \multicolumn{1}{|c|}{ Principio } & Número de veces encontrado \\
\hline Voluntariedad & 13 \\
\hline Confidencialidad & 10 \\
\hline Flexibilidad & 8 \\
\hline Otros & 4 \\
\hline
\end{tabular}

Fuente: elaboración propia

En cuanto a la voluntariedad, en trece (13) de los textos hay menciones directas o indirectas a este principio. Hay unanimidad en admitir que este debe ser expreso, tanto para la persona del ofensor/acusado como para la víctima/perjudicado. Las formas en las que se han dado fueron:

- Como consentimiento que otorgan las partes que puede ser revocado.

- Como una obligación del mediador de interrumpir la mediación cuando crea que hay algún vicio en el consentimiento voluntario.

- Como una posibilidad que tienen las partes de elegir siempre que se les haya dado la información necesaria para ser conscientes de lo que están aceptando (consentimiento informado).

Con respecto a la confidencialidad también esta viene ampliamente reflejada, tanto para las partes como para el mediador en mayor medida, y existe la exigencia de reserva. Esto se puede ver, por ejemplo, en la Ley de Hungría CXXIII, artículos 3.5 y 3.6: "El mediador - salvo que la ley disponga otra cosa - no tiene ninguna obligación de revelar datos, cifras y circunstancias de las que tenga conocimiento del contexto de las actividades de mediación". También está presente la imposibilidad de utilizar la información obtenida en el proceso de mediación para la resolución del proceso penal que se inicia con el hecho delictivo. En este caso, hay textos muy tajantes que impiden lo anterior, 
como la ley de mediación penal de Portugal, artículo 4.5: "El contenido de las sesiones de mediación es confidencial, no puede ser valorado como prueba en el proceso judicial", y otros admiten la posibilidad de saltarse el principio cuando concurran circunstancias especiales ${ }^{24}$.

En cuanto al principio de flexibilidad, varios textos lo nombran al aludir al proceso de mediación en un sentido amplio. La Ley de Portugal de mediación penal, artículo 4.1 dice: “... mediación es un proceso informal y flexible", o como lo establece Bélgica en el Código Procesal Penal en su artículo 1735, apartado 2: "La mediación puede cubrir la totalidad o parte de la disputa". En el apartado Otros, como subcategoría en el análisis, se han recogido otros principios de la mediación:

- El que hace referencia a que la mediación es un proceso personalísimo, en el que solo pueden intervenir directamente las partes del conflicto en persona.

- La imparcialidad del mediador también se establece como principio, como hacen Portugal o Polonia, pero se ha recogido y estudiado ampliamente en la categoría actividad del mediador.

- Rumania, uno de los países estudiados, hace alusión al principio de no discriminación como uno de los que los servicios de mediación deberían hacer gala.

Categoría 7: Principios específicos de la mediación penal

En relación con los anteriores principios examinados, estos aparecen en mucha menor medida, con una o dos referencias a cada uno de ellos en la totalidad de los textos. La cantidad de referencias encontradas se muestran en la tabla 6 :

24 Como sería que ambas partes estén de acuerdo en revelar información o que haya más actividad delictiva, como recogen los textos legales franceses. 
Tabla 6

Distribución de los principios específicos de la mediación penal

\begin{tabular}{|l|c|}
\hline \multicolumn{1}{|c|}{ Principio } & Número de veces encontrado \\
\hline Reconocimiento & 2 \\
\hline Proporcionalidad & 1 \\
\hline Complementariedad & 1 \\
\hline Oficialidad & 3 \\
\hline Gratuidad & 5 \\
\hline Otros & 3 \\
\hline
\end{tabular}

Fuente: elaboración propia

El principio de reconocimiento aparece contemplado de forma clara en el artículo 3 de la ley de Suecia de mediación penal de la siguiente manera: "La mediación tendrá por objetivo que el delincuente pueda tener un mayor conocimiento de las consecuencias del delito".

En cuanto a la proporcionalidad que se ha de alcanzar en los acuerdos de mediación penal con respecto al daño causado, solo la Ley húngara CXXIII, en el artículo 13.3 se hace eco: "Las obligaciones asumidas en el contrato deben cumplir con la ley, deben ser razonables y no en conflicto con las buenas costumbres".

Los principios de complementariedad de la mediación con el sistema de justicia penal y el principio de oficialidad están muy relacionados y se desprenden de muchos de los textos, ya que en casi todos los países los procesos de mediación penal se llevan a cabo bajo el ala del sistema judicial. Solo algunos países reflejan esta característica de manera directa, como Hungría, en el artículo 13.5 de la ley de mediación penal: "Los documentos del procedimiento de mediación que se generan en el proceso penal en el que la mediación se llevó a cabo, no se pueden utilizar como prueba, excepto con los documentos y el informe del mediador como resultado del acuerdo de mediación". 
En muchos de los textos analizados hay una referencia explícita al principio de gratuidad, lo que no deja lugar a dudas de que ni la víctima ni el acusado tienen que pagar por el servicio de mediación, por lo que se da a entender que son fondos públicos los que tienen que hacerse cargo de los gastos derivados del procedimiento. En la subcategoría Otros de esta categoría se han recogido otras premisas que pueden valer como principios pero que no están reconocidas como tales, como podría ser el recogido en la Ley de Suecia, artículo 9, que permite a la víctima una serie de derechos como: "...la parte perjudicada deberá tener la oportunidad de hablar sobre su experiencia de la delincuencia y sus consecuencias", lo que podría entenderse como el "derecho al desahogo de la víctima" en el proceso de mediación.

Categoría 8: Repercusiones del procedimiento de mediación

Las repercusiones del proceso de mediación encontradas en los textos recaen principalmente en el acusado/agresor/ofensor. La consecuencia más común de la mediación es la suspensión del procedimiento penal, institución en la que el agresor queda supeditado durante un tiempo a no realizar ningún ilícito penal so pena de reabrir la causa penal; acortar la pena impuesta en función de los esfuerzos del agresor por reparar el daño causado a la víctima y además también existe la posibilidad de retirar la denuncia, si hay voluntad por parte de la víctima sin responsabilidad penal para el agresor en infracciones leves, aunque esta posibilidad solo existe en algunos países. Con respecto al sistema de justicia, las repercusiones que se plantean van enfocadas a un cambio en la forma de entender el delito y de minimizarlo todo lo posible, como en el caso de la ley sueca que establece: "El objetivo debe ser reducir el impacto negativo de la delincuencia". La víctima y su entorno apenas son contemplados en los efectos de la mediación penal de las leyes, y las reseñas encontradas aluden a consecuencias de nivel psicológico de afrontamiento del hecho delictivo sin entrar en ninguna otra consideración de carácter procesal, como en el caso de Suecia en la Ley (2002:445), 
artículo 3:"A la víctima se le da la oportunidad de procesar sus experiencias” y la República Checa, Ley 257/2000 de Libertad Condicional y Medición, artículo 4.3: "El servicio de libertad condicional y mediación también ayuda en la eliminación de las consecuencias del delito a la víctima y las demás personas afectadas por la delincuencia". 


\section{CONCLUSIONES Y DISCUSIÓN}

La fecha de los textos analizados nos muestra que la mediación penal es bastante reciente en la Unión Europea. Cada uno de los textos presenta sus variaciones y matices en atención al sistema de justicia, pero su introducción ya es una realidad y su afianzamiento como práctica complementaria al sistema judicial es solo cuestión de tiempo. Uno de los rasgos a destacar es que los países que recogen la mediación penal en una normativa autónoma lo hacen con mucho más detalle, lo que crea una base sólida que a la larga se traduce en un mayor conocimiento del terreno de trabajo de los mediadores y en una mayor seguridad jurídica que reciben por el respaldo de una normativa más completa. El objetivo a lograr, desde nuestro punto de vista, es que con el tiempo cada uno de los países contará con una norma autónoma para desarrollar la mediación penal con más detalle y calado.

Otra de las conclusiones que se pueden extraer de esta comparativa europea de leyes es que no es necesaria una separación tajante entre lo que es mediable o no en el ámbito penal para funcionar. Esta es una cuestión muy espinosa en la que se tienen que valorar variables como la peligrosidad, la condición de la víctima para enfrentarse al proceso de mediación y a su agresor, las condiciones del propio agresor para reparar a la víctima, etc., que en definitiva tienen que ser evaluadas por profesionales para decidir si es posible la mediación. Otra cuestión es la existencia de infracciones penales que tienen la prohibición taxativa de poder ser mediables o sometidas a proceso restaurativo, como las que se dan en el seno de una relación conyugal, la violencia sexual o los delitos cometidos por una organización criminal ${ }^{25}$. Por todo ello, es posible operar en la práctica sin una lista numerus clausus de infracciones mediables, ya sean delitos o faltas, y con la práctica profesional y el paso del tiempo, podrá decidirse si se media o no en función del tipo penal, sino de las

25 Por cuestiones sociales y criminológicas son más delicadas de tratar y normalmente tienen un refuerzo extra en la criminalización por la política criminal de cada país. 
características del caso valoradas adecuadamente. La tendencia actual en el entorno europeo es la de llevar la mediación a los delitos y no únicamente a las faltas, aunque en la mayoría en su modalidad de menos graves, lo cual indica que cada vez más se va apostando por ilícitos de mayor gravedad.

Por otra parte, el hecho de que en los textos analizados se encontraran escasas referencias teóricas a la mediación penal es otro indicativo de la falta de implantación suficiente de la mediación penal como ámbito de estudio. El hecho de que ya se den algunas permite que el conocimiento de la mediación vaya calando y empiecen a hacerse producciones teóricas legislativas más elaboradas. El problema que se detecta es la falta de fundamentación de la mediación penal en los países de la Unión Europea con el paradigma de la justicia restaurativa, es decir, en la reparación del daño y la restauración de la paz social que se quebranta con el delito. La mediación penal sin la base de la justicia restaurativa y enfocada únicamente al acuerdo produciría con el tiempo que las prácticas de mediación en el ámbito intrajudicial penal se fueran devaluando, lo que las convertiría en uno más de los trámites judiciales, como la conciliación civil.

Los principios de la mediación están bien delineados en los textos, que hacen un desarrollo adecuado y con la necesaria matización para poder ser aplicados al proceso de mediación penal. Por otra parte, los principios específicos de la mediación penal han tenido un papel secundario en los textos no acorde con la importancia que tienen para el buen desarrollo de la práctica de la mediación penal. Del estudio de este apartado, se concluyen la importancia y la necesidad de que el proceso de mediación penal se lleve a cabo en el seno de un procedimiento jurisdiccional penal, para poder devolver al mismo todos los resultados del proceso de mediación; se destaca que el proceso de mediación penal tiene que ser necesariamente intrajudicial tal como está establecido en los instrumentos legales de los países de la Unión Europea.

En cuanto al estudio de las consecuencias que se derivan de la participación en un proceso de mediación, los hallazgos úni- 
camente se refieren a la posibilidad de minimizar la respuesta penal o desistir de la acción penal con la consecución de acuerdos en mediación. Bajo nuestra consideración, creemos que la mediación penal puede producir resultados que van más allá de estas dos consecuencias contempladas, una para delitos graves y a otra para delitos leves, lo que deja al descubierto un gran abanico de infracciones cuya correspondencia en resultados con base en el proceso de mediación no está cubierta y que podrían ser muy interesantes de cara a la reparación del daño, y cambiar la naturaleza retributiva de la justicia penal.

A modo de conclusión general, ya es posible comparar la legislación sobre mediación penal - aunque es reciente y su avance es lento-, en los países del ámbito europeo. Existe la posibilidad de elaborar muchas propuestas de mejora y adaptarlas a países que aún carecen de normativa específica, como España $^{26}$. Quizá el peor enemigo de la mediación penal sea su desconocimiento como una herramienta con grandes posibilidades para la sociedad y en el entramado del sistema judicial. Por todo ello, el principal reto es darle visibilidad a esta práctica y por eso, estos trabajos son necesarios, porque con ellos cada día la mediación se extiende.

Las bases académicas de la mediación penal son el primer paso para conseguir su introducción en los juzgados españoles para poder formar a profesionales y llegar a las personas que no conocen esta práctica, con independencia de que hayan tenido qué ver o no con una actividad delictiva $\mathrm{y}$, simplemente, comenzar a andar.

26 Recientemente, en España, con la reforma del Código Penal, la Ley de Enjuiciamiento Criminal y el Estatuto de la Víctima del Delito se ha permitido la "entrada legislativa" de la mediación penal pero queda un largo recorrido para que las instancias judiciales la reconozcan como una respuesta legítima y adecuada, que solo puede conseguirse con años de práctica y un mayor desarrollo de esta materia en los textos legales. 


\section{BIBLIOGRAFÍA}

\section{Libros}

Barona-Vilar, Silvia, Mediación penal: fundamento, fines y régimen jurídico (Tirant lo Blanch, Valencia, 2011).

Folberg, Jay \& Taylor, Alison, Mediation: A Comprehensive Guide to Resolving Conflicts without Litigation (Wiley, Jossey Bass, San Francisco, 1984).

Gordillo-Santana, Luis F., La justicia restaurativa y la mediación penal (Iustel, Madrid, 2007).

Hernández-Sampieri, Roberto; Fernández-Collado, Carlos \& Baptista-Lucio, María del Pilar, Metodología de la investigación (McGraw-Hill, México, 2010). Disponible en: https://www.esup.edu.pe/descargas/dep_investigacion/Metodologia $\% 20 \mathrm{de} \% 20$ la\%20investigaci\%C3\%B3n\%205ta\%20Edici\%C3\%B3n.pdf

Moore, Christopher W., Natural Resources Conflict Management (Accord Associates, Boulder, Colorado, 1982).

Moore, Christopher W., The Mediation Process: Practical Strategies for Resolving Conflict (Jossey Bass Wiley, San Francisco, 2003).

\section{Colaboración en obras colectivas}

Puy-Muñoz, Francisco de Paula, La expresión "mediación jurídica”: un análisis tópico, en Mediación y solución de conflicto. Habilidades para una necesidad emergente, 21-36 (Helena Soleto-Muñoz \& Milagros María Otero-Parga, coords., Tecnos, Madrid, 2007).

\section{Revistas}

Domingo de la Fuente, Virginia, Contexto teórico-práctico de la justicia restaurativa en Europa con especial atención a España, 4 Revista Criminología y Justicia, 7083 (2012). Disponible en: http://dialnet.unirioja.es/servlet/articulo?codigo=4063084

Guimarães, José Augusto Chaves; Moraes, João Batista Ernesto de \& Guarido, Maura Duarte Moreira, Análisis documental de contenido de textos narrativos: bases epistemológicas y perspectivas metodológicas, 1 Ibersid, Revista de Sistemas de Información y Documentación, 93-99 (2007). Disponible en: http://www.ibersid. eu/ojs/index.php/ibersid/article/view/3267/3028

Saéz-Valcárcel, Ramón, La mediación penal, una metodología judicial para ocuparse de la reparación y de la resocialización, 2062 Boletín del Ministerio de Justicia, 1757-1770 (junio de 2008).

Segovia-Bernabé, José Luis, Mediación penal comunitaria y justicia restaurativa. Una perspectiva ética y jurídica, en Mediación penal y penitenciaria. 10 años de camino, 17-56 (Fundación Ágape, Art\&Press, Madrid, 2010). 
Villarreal-Sotelo, Karla, La víctima, el victimario y la justicia restaurativa, 7 Rivista di Criminologia, Vittimologia e Sicurezza, 1, $43-57$ (2013). Disponible en: http:// www.vittimologia.it/rivista/articolo_villarrealsotelo_2013-01.pdf

\section{Working paper}

Andréu-Abela, Jaime, Las técnicas de análisis de contenido: una revisión actualiza$d a$ (Centro de Estudios Andaluces, Junta de Andalucía, Working paper S200103, 2001). Disponible en: http://public.centrodeestudiosandaluces.es/pdfs/S200103.pdf

Ríos-Martín, Julián Carlos, Justicia restaurativa y mediación penal. Una apuesta por el diálogo y la disminución de la violencia (2005-2008). Disponible en: http:// www.poderjudicial.es/stfls/cgpj/Doc\%20Temporales/DocsPublicacion/FICHERO/ PONENCIA\%20JULIAN\%20RIOS_1.0.0.pdf

Ríos-Martín, Julián Carlos; Martínez-Escamilla, Margarita; Segovia-Bernabé, José Luis; Gallego-Díaz, Manuel; Cabrera, Pedro \& Jiménez-Arbelo, Montserrat, Justicia restaurativa y mediación penal. Análisis de una experiencia (2005-2008). (2008). Disponible en: http://www.google.es/url?sa=t\&rct=j\&q=\&esrc=s\&sour $\mathrm{ce}=$ web $\& \mathrm{~cd}=1 \& \mathrm{ved}=0 \mathrm{CCEQFjAA} \& u \mathrm{rl}=\mathrm{http} \% 3 \mathrm{~A} \% 2 \mathrm{~F} \% 2 \mathrm{Fwww}$.poderjudicial. es\%2Fstfls\%2Fcgpj\%2FDoc\%2520Temporales\%2FDocsPublicacion\%2FFICH ERO\%2FInvestigaci\%25C3\%25B3n\%2520del\%2520CGPJ\%25202008\%2520 2b\%2520\%25282\%2529_1.0.0.pdf\&ei=VEzTVMisHoHsUJDug0g\&usg=AFQjC NHVivi8vNc-v26E135zE4-Uh2L63g\&bvm=bv.85142067,d.d24

\section{Tratados internacionales}

Organización de Naciones Unidas, ONU, Asamblea General, Declaración sobre los principios fundamentales de justicia para las víctimas de delitos y del abuso de poder, A/RES 40/34, Resolución 40/34, 29 de noviembre de 1985. Disponible en: http://www.ohchr.org/SP/ProfessionalInterest/Pages/VictimsOfCrimeAndAbuse OfPower.aspx, https://www.unodc.org/pdf/criminal_justice/Compendium_UN_ Standards_and_Norms_CP_and_CJ_Spanish.pdf

Organización de Naciones Unidas, ONU, Asamblea General, Reglas Mínimas de las Naciones Unidas sobre las medidas no privativas de libertad, Reglas de Tokio, adoptadas por la Asamblea General en su resolución 45/110, 14 de diciembre de 1990. Disponible en: http://www.hchr.org.co/documentoseinformes/documentos/ carceles/1_Universales/B\%E1sicos/6_Prevencion_delito_tratamiento_delinc/1161_ Reglas_m\%EDn_NU_medidas_no_priva_libert.pdf, https://www.unodc.org/pdf/ criminal_justice/Compendium_UN_Standards_and_Norms_CP_and_CJ_Spanish. pdf

Organización de Naciones Unidas, ONU, Consejo Económico y Social, ECOSOC, Elaboración y aplicación de medidas de mediación y justicia restaurativa en materia de justicia penal, Resolución 1999/26, 28 de julio de 1999. Disponible en: https://www. unodc.org/documents/commissions/CCPCJ/Crime_Resolutions/1990-1999/1999/ ECOSOC/Resolution_1999-26.pdf 
Organización de Naciones Unidas, ONU, Consejo Económico y Social, ECOSOC, Resolución 2000/14, 27 julio de 2000. Disponible en: https://www.unodc.org/ documents/commissions/CCPCJ/Crime_Resolutions/2000-2009/2000/ECOSOC/ Resolution_2000-14.pdf

Organización de Naciones Unidas, ONU, Consejo Económico y Social, ECOSOC, Declaración del Consejo Económico y Social de la ONU, 18 de abril de 2002.

Unión Europea, Comité de Ministros del Consejo de Europa, Recomendación R(99)19, 15 de septiembre de 1999. Disponible en: https://search.coe.int/cm/Pages/result_ details.aspx?ObjectID $=090000168062 \mathrm{e} 02 \mathrm{~b}$

Unión Europea, Consejo de la Unión Europea, Decisión marco del Consejo de 15 de marzo de 2001 relativa al estatuto de la víctima en el proceso penal (2001), 2001/220/JAI, L 82/1 Diario Oficial de las Comunidades Europeas, 22 de marzo de 2001. Disponible en: http://eur-lex.europa.eu/legal-content/ES/ALL/?uri=CELEX:32001F0220

Unión Europea, Parlamento Europeo \& Consejo de la Unión Europea, Directiva 2008/52/ CE del Parlamento Europeo y del Consejo de 21 de mayo de 2008 sobre ciertos aspectos de la mediación en asuntos civiles y mercantiles, L 136/3 Diario Oficial de la Unión Europea, DOUE, 24 de mayo de 2008. Disponible en: http://eur-lex. europa.eu/LexUriServ/LexUriServ.do?uri=OJ:L:2008:136:0003:0008:Es:PDF

Unión Europea, Parlamento Europeo \& Consejo de la Unión Europea, Directiva 2012/29/ UE del Parlamento Europeo y del Consejo, 25 de octubre de 2012, por la que se establecen normas mínimas sobre los derechos, el apoyo y la protección de las víctimas de delitos, y por la que se sustituye la Decisión marco 2001/220/JAI del Consejo, 315 Diario Oficial de la Unión Europea, 14 de noviembre de 2012. Disponible en: http://eur-lex.europa.eu/legal-content/ES/TXT/?uri=CELEX:32012L0029

\section{Normatividad internacional}

Alemania, Código Penal, StGB, Strafgesetzbuch. https://www.gesetze-im-internet.de/ englisch_stgb/englisch_stgb.pdf, https://www.gesetze-im-internet.de/stgb/

Alemania, Código de Procedimiento Penal, StPO, Strafprozeßordnung. https://www. gesetze-im-internet.de/englisch_stpo/index.html, https://www.gesetze-im-internet. de/stpo/

Austria, Código Penal. Disponible en: http://www.ris.bka.gv.at/GeltendeFassung.wxe ?Abfrage $=$ Bundesnormen $\&$ Gesetzesnummer $=10002296$

Austria, Código de Procedimiento Penal. Disponible en: http://www.wipo.int/wipolex/ es/text.jsp?file_id=235569

Bélgica, Código de procedimiento Judicial-penal, Code Judiciaire. Disponible en: http:// www.droitbelge.be/codes.asp\#jud

España, Ley 4/2015, 27 de abril, del Estatuto de la víctima del delito, 101 Boletín Oficial del Estado, BOE, 28 de abril de 2015. Disponible en: https://www.boe.es/diario_boe/ txt.php?id=BOE-A-2015-4606

España, Ley Orgánica 10/1995, 23 de noviembre, Código Penal, incluye la reforma del 1 de julio de 2015, 281 Boletín Oficial del Estado, BOE, 24 de noviembre de 1995. 
Disponible en: https://www.boe.es/buscar/act.php?id=BOE-A-1995-25444

España, Real decreto, 14 de septiembre de 1882, por el que se aprueba la Ley de Enjuiciamiento Criminal, actualizado, 281 Boletín Oficial del Estado, BOE, 17 de septiembre de 1882. Disponible en: https://www.boe.es/buscar/act.php?id=BOE-A-1882-6036

Finlandia, Ley de conciliación en casos civiles y penales (1015/2005), Ministerio de Asuntos Sociales y Salud. Disponible en: http://www.finlex.fi/fi/laki/kaannokset 12005/en20051015.pdf

Francia, Código de Procedimiento Penal. Disponible en: https://www.legifrance.gouv. fr/affichCode.do?cidTexte $=$ LEGITEXT000006071154\&dateTexte $=20160918$

Francia, Código Penal. Disponible en: https://www.legifrance.gouv.fr/affichCode.do ?cidTexte=LEGITEXT000006070719\&dateTexte $=20160918$, versión que entrará en vigor en 2017: https://www.legifrance.gouv.fr/affichCode.do;jsessionid=B10D 327A0AFD4BEDCEF369C69DF040B6.tpdila12v_3?cidTexte=LEGITEXT00000 $6070719 \&$ dateTexte $=20170101$

Hungría, Ley CXXIII de 2006 aplicable en materia penal, actividades de intermediación.

Hungría, Código Penal, Ley IV de 1978, reformada en 2012. Disponible en: http://www. legislationline.org/documents/section/criminal-codes

Hungría, Ley XIX de 1998 del Código de Procedimiento Criminal, 18 de agosto de 2005. Disponible en: https://www.unodc.org/cld/v3/sherloc/legdb/search.html

Italia, Decreto Legislativo 274, 28 de agosto de 2000. Disposiciones sobre la jurisdicción penal del juez de paz, de conformidad con el artículo 14 de la Ley 468, 24 de noviembre de 1999. Disponible en: http://www.camera.it/parlam/leggi/deleghe/00274dl.htm

Luxemburgo, Reglamento del Gran Ducado, 24 de julio de 2011, que modifica el Reglamento del Gran Ducado de 21 de junio de 1993 relativa al procedimiento de mediación previsto en el artículo 69 del Código de Seguridad Social. Disponible en: http://www.legilux.public.lu/leg/a/archives/2011/0158/a158.pdf

Luxemburgo, Reglamento del Gran Ducado, 25 de junio de 2012, que fija los procedimientos de aprobación de las funciones del Defensor del Pueblo legal y la familia, el programa de formación específica en mediación y la celebración de una reunión de información libre (formación en mediación). Disponible en: http://www.legilux. public.lu/leg/a/archives/2012/0134/a134.pdf\#page $=6$

Polonia, Código de Procedimiento Penal. Ley de 6 de junio de 1997. Disponible en: http://www.wipo.int/wipolex/es/details.jsp?id=3512

Polonia, Código Ético de los mediadores, 19 de mayo de 2008. Disponible en: http:// ms.gov.pl/Data/Files/_public/mediacje/adr1/kodeksetyczny.pdf

Polonia, Código Penal, 6 de junio de 1997. Disponible en: https://www.imolin.org/doc/ amlid/Poland_Penal_Code1.pdf

Polonia, Ley sobre la conducta de la mediación en materia penal, 13 de junio de 2003.

Polonia, Normas para la formación de los mediadores, Regla adoptada por el Consejo Social de Métodos Alternativos de Resolución de Conflicto y Resolución de Disputas en el Ministerio de Justicia, 29 de octubre 2007. Disponible en: http://ms.gov.pl/ Data/Files/_public/mediacje/adr1/standardyszkoleniamediatorow.pdf

Portugal, Ley 21/2007, 12 de junio, que crea un plan de mediación, de conformidad 
con el artículo 10 de la Decisión marco 2001/220/JAI del Consejo, de 15 de marzo sobre el estatuto de la víctima en el proceso penal. Promulgada el 30 de mayo de 2007. Disponible en: http://www.pgdlisboa.pt/leis/lei_mostra_articulado. php?nid=1459\& tabela $=$ leis

República Checa, Ley 359/1999, recopilación, sobre la protección infantil (Ley de Libertad Vigilada y Mediación). Disponible en: http://www.mpsv.cz/files/clanky/14897/ Act_359-1999.pdf

Suecia, Ley 2002:445. Disponible en: https:/www.riksdagen.se/sv/dokument-lagar/ dokument/svensk-forfattningssamling/lag-2002445-om-medling-med-anledningav-brott_sfs-2002-445

\section{Casos}

España, Audiencia Provincial de Madrid, Sentencia AP Madrid, Sección 17, 621/2015 de 16 de septiembre (Recurso 6037/2013), magistrado ponente María Jesús CoronadoBuitrago. Disponible en: http://www.poderjudicial.es/cgpj/es/Temas/Mediacion/ Normativa-y-jurisprudencia/Sentencias/Materia-penal/Sentencia-AP-Madrid-Seccion-17--n--621-2015-de-16-de-septiembre--rec--6037-2013- 